\title{
Generation of Wholly Thermoplastic Composites and Their Processing in Additive Manufacturing
}

\author{
Tianran Chen*, Jier Han and Donald G. Baird \\ Macromolecules Innovation Institute \\ Department of Chemical Engineering \\ Virginia Tech \\ Blacksburg, VA 24061 \\ *Email: tianran@vt.edu
}

3D printing has attracted great interest over the past three decades due to its high precision, less waste generation and design freedom[1-3]. One of the major challenges $3 \mathrm{D}$ printing is the poor mechanical performance of pure polymer parts. Researchers used traditional carbon and glass fiber reinforced composites to overcome this issue [4-7]. The traditional fibers can improve the mechanical properties of printed parts. However, the manufacturing techniques and printing process restrict the overall performance of the printed parts. Thermotropic liquid crystalline polymer (TLCP) is another reinforcement which offers lighter weight, lower viscosity, excellent mechanical performance and great recyclability [8-17]. TLCPs are capable of forming extended conformations when subjected to extensional or shear deformation. The formation of highly orientated molecular structure enables the generation of high mechanical properties .

In this study, polyamide was reinforced with TLCP by the dual-extrusion technique to generate high performance composite filaments [18]. Rheological tests were used to optimize the processing conditions of the dual-extrusion process, which could minimize the degradation of matrix polymer. High performance and lightweight fiber-reinforced composite parts were fabricated by utilizing the fused filament fabrication (FFF) technique. The composite filaments were printed at the temperature below the melting point of TLCP to avoid the relaxation of TLCP. The mechanical performances of printed parts are greater than 3D printed parts which are reinforced by conventional fibers. 


\section{Reference}

1. Ngo, T. D.; Kashani, A.; Imbalzano, G.; Nguyen, K. T. Q.; Hui, D., Additive manufacturing (3d printing): A review of materials, methods, applications and challenges. Composites Part BEngineering 2018, 143, 172-196.

2. Wang, X.; Jiang, M.; Zhou, Z. W.; Gou, J. H.; Hui, D., 3d printing of polymer matrix composites: A review and prospective. Composites Part B-Engineering 2017, 110, 442-458.

3. Yang, C. C.; Tian, X. Y.; Liu, T. F.; Cao, Y.; Li, D. C., 3d printing for continuous fiber reinforced thermoplastic composites: Mechanism and performance. Rapid Prototyping Journal 2017, 23, 209-215.

4. $\quad$ Matsuzaki, R.; Ueda, M.; Namiki, M.; Jeong, T. K.; Asahara, H.; Horiguchi, K.; Nakamura, T.; Todoroki, A.; Hirano, Y., Three-dimensional printing of continuous-fiber composites by in-nozzle impregnation. Scientific Reports 2016, 6.

5. Hwang, S.; Reyes, E. I.; Moon, K.-s.; Rumpf, R. C.; Kim, N. S., Thermo-mechanical characterization of metal/polymer composite filaments and printing parameter study for fused deposition modeling in the $3 \mathrm{~d}$ printing process. Journal of Electronic Materials 2015, 44, 771 777.

6. Shofner, M. L.; Rodriguez-Macias, F. J.; Vaidyanathan, R.; Barrera, E. V., Single wall nanotube and vapor grown carbon fiber reinforced polymers processed by extrusion freeform fabrication. Composites Part a-Applied Science and Manufacturing 2003, 34, 1207-1217.

7. Li, N. Y.; Li, Y. G.; Liu, S. T., Rapid prototyping of continuous carbon fiber reinforced polylactic acid composites by 3d printing. Journal of Materials Processing Technology 2016, 238, 218-225.

8. Gray, R. W.; Baird, D. G.; Bohn, J. H., Thermoplastic composites reinforced with long fiber thermotropic liquid crystalline polymers for fused deposition modeling. Polymer composites 1998, 19, 383-394.

9. McLeod, M. A.; Baird, D. G., The influence of processing variables on the mechanical properties of injection molded pregenerated microcomposites. Composites Part B-Engineering 1999, 30, 297-308.

10. Tjong, S., Structure, morphology, mechanical and thermal characteristics of the in situ composites based on liquid crystalline polymers and thermoplastics. Materials Science Engineering: $R$ : Reports

2003, 41, 1-60.

11. Postema, A.; Fennis, P. J. P., Preparation and properties of self-reinforced polypropylene/liquid crystalline polymer blends. 1997, 38, 5557-5564.

12. Han, J. Y.; Chen, T.; Mu, Q.; Baird, D. G., Thermotropic liquid crystalline polymer reinforced polypropylene composites enhanced with carbon nanotubes for use in fused filament fabrication. Polymer composites 2021.

13. Chen, T., The influence of recycling on thermotropic liquid crystalline polymer and glass fiber composites. 2021.

14. Chen, T.; Mansfield, C. D.; Ju, L.; Baird, D. G., The influence of mechanical recycling on the properties of thermotropic liquid crystalline polymer and long glass fiber reinforced polypropylene. Composites Part B: Engineering 2020, 200, 108316.

15. Chen, T. Generation of recyclable liquid crystalline polymer reinforced composites for use in conventional and additive manufacturing processes. Virginia Tech, 2021. 
16. Han, J. Y.; Chen, T.; Baird, D. G., Generation of nylon copolymer reinforced with carbon nanotubes and thermotropic liquid crystalline polymers for use in fused filament fabrication. Polymer composites 2021, 42, 4328-4341.

17. Chen, T.; Kazerooni, D.; Ju, L.; Okonski, D. A.; Baird, D. G., Development of recyclable and high-performance in situ hybrid tlcp/glass fiber composites. Journal of Composites Science 2020, 4, 125.

18. Chen, T.; Han, J. Y.; Okonski, D. A.; Kazerooni, D.; Ju, L.; Baird, D. G., Thermotropic liquid crystalline polymer reinforced polyamide composite for fused filament fabrication. Additive Manufacturing 2021, 40, 101931. 